\title{
Conservative management of pregnancy in diabetic women
}

\author{
J MURPHY, J PETERS, P MORRIS, T M HAYES, J F PEARSON
}

\begin{abstract}
In 1979 the obstetric management of pregnancies in diabetic women in Cardiff was changed from elective delivery at 37-38 weeks to delivery at term. This change was facilitated by home monitoring of blood glucose concentrations and improved techniques for assessing fetal wellbeing. There were 35 pregnancies in insulin dependent diabetics in $1972-8$ and 45 in 1979-82. The quality of diabetic control during pregnancy was equally good in both periods. The average gestation at final admission to hospital increased from 30 to 37 weeks. Amniocentesis to assess fetal pulmonary maturity was necessary in 26 patients $(74 \%)$ in the first period of study and in only four $(9 \%)$ in the second. Gestational age at delivery increased from 37.4 to 39.4 weeks after the change in policy. The proportion of mothers entering spontaneous term labour and delivering vaginally increased from $14.3 \%$ to $37 \cdot 8 \%$. The mean birth weight of live born, singleton infants increased from $3090 \mathrm{~g}$ to $3650 \mathrm{~g}$, the feeding pattern improved, and respiratory problems were less common.

Morbidity was reduced and perinatal mortality was not increased with conservative management of pregnancy in diabetic women.
\end{abstract}

University Hospital of Wales, Cardiff CF4 4XN

J MURPHY, MRCP, DCH, senior registrar, department of child health

$P$ MORRIS, MB, MRCOG, senior registrar, department of obstetrics and gynaecology

T M HAYES, MB, FRCP, consultant physician, department of medicine

Welsh National School of Medicine, Cardiff CF4 4XN

J PETERS, MD, MRCP, lecturer, department of medicine

J F PEARSON, MD, FRCOG, reader, department of obstetrics and gynaecology

Correspondence to: $\mathrm{Mr} \mathrm{J}$ F Pearson.

\section{Introduction}

Scrupulous control of maternal plasma glucose concentrations has been associated with a considerable reduction in perinatal mortality in diabetic women. ${ }^{1}$ The timing of delivery is also a critical determinant of fetal outcome. Usual obstetric practice has been to deliver at about 37 weeks to reduce the risk of spontaneous intrauterine death, ${ }^{2}$ but this increases the likelihood of problems due to prematurity. ${ }^{3}$ The increasing use of home monitoring of glucose concentrations and the ability to monitor fetal wellbeing with fetal movement counts and cardiotocography led our unit to change its policy in 1979. Instead of undergoing induction of labour at 37-38 weeks diabetic mothers were allowed to enter spontaneous labour at term. We examined retrospectively the effects of this change in policy on medical and obstetric management and on perinatal outcome.

\section{Patients and methods}

\section{METHODS}

1973-8-From 1973 to 1978 control of diabetes during pregnancy was assessed by single weekly laboratory estimations of plasma glucose concentrations and by monitoring at home by urine testing. Unsatisfactory control of diabetes necessitated admission for stabilisation, and all mothers were admitted routinely at 30 weeks' gestation for the remainder of their pregnancy. While patients were in hospital plasma glucose concentrations were monitored on three days each week, samples being taken four times a day (before the three main meals and before bed time). Gestational age was confirmed by ultrasound in every patient. Growth was assessed by serial cephalometry and fetal wellbeing by serial oestriol assay. Amniocentesis was usually performed during the 37th week to assess fetal pulmonary maturity, and delivery was undertaken at 38 weeks. Delivery was either by elective caesarean section or by induction of labour. In general, vaginal delivery was the favoured option. Progress of labour was monitored with composite partograms. Epidural analgesia was usually given, and fetal heart rate was monitored electronically in all cases. Induction was always by simultaneous low amniotomy and 
infusion of oxytocin with a Cardiff fully automatic infusion system Mk IV (Pye Dynamics). Caesarean section during labour was readily undertaken if there was evidence of fetal distress or if an abnormal pattern of labour developed.

1979-82-At the beginning of 1979 we changed the policy on both obstetric and medical management of pregnant diabetic women. Clinical and ultrasonic measurements of fetal growth remained standard procedure, but the techniques of antenatal cardiotocography and of counting fetal movements, which we had evaluated previously, also became part of our routine management and displaced hormonal tests of placental function. All pregnant diabetic women were instructed in home monitoring of their blood glucose concentrations with BM 20-800 sticks (Boehringer-Mannheim), and every week they brought a series of preprandial samples taken at home to the clinic in capillary tubes for laboratory checking. Good control was represented by preprandial plasma glucose concentrations of $<7 \mathrm{mmol} / \mathrm{l}(<126 \mathrm{mg} / 100 \mathrm{ml})$ during the first and second trimesters and $<6 \mathrm{mmol} / 1(<108 \mathrm{mg} / 100 \mathrm{ml})$ in the third trimester and by glycosylated haemoglobin concentrations, which were measured monthly, within normal limits for our laboratory (3-8\%). Patients complying with these criteria and without obstetric problems continued to term as outpatients. Normally patients were allowed to go into spontaneous labour irrespective of gestational age. Thus amniocentesis for evaluation of fetal pulmonary maturity was performed only when elective premature delivery was necessary.

\section{MOTHERS}

We studied 80 pregnancies, including one twin pregnancy, in 67 mothers, 35 in the first period (White's class B20; C13; D1; R1) and 45 in the second (White's class B15; C20; D9; R1). The larger numbers in the second period reflected increased referral to the medical antenatal clinic. Women subsequently found to have had gestational diabetes, whether insulin dependent or not, were excluded from this study. All patients were maintained with injections of short and intermediate acting insulin given twice daily. From 1976 these injections were predominantly of the highly purified monocomponent type. Any necessary adjustments in dosage were made either by the patients themselves on the basis of home monitoring of glucose concentrations or when the patients attended the weekly clinic. After 1975 diabetes was managed in labour with continuous low dose (1-2 IU/h) infusion of insulin.

\section{INFANTS}

Infants were managed as aescribed by Gamsu." Deliveries were attended by the neonatal resident, and resuscitation was carried out promptly if needed. In the first period of study all infants were admitted to the special care baby unit for observation, whereas in

TABLE I-Mean (SD) maternal plasma glucose concentrutions (mmol/l) before and after change in obstetric management

\begin{tabular}{lccc}
\hline & First trimester & Second trimester & Third trimester \\
\hline $1973-8$ & $6 \cdot 8(2 \cdot 4)$ & $6 \cdot 3(1 \cdot 2)$ & $5 \cdot 4(0 \cdot 7)$ \\
$1979-82$ & $6.8(2 \cdot 3)$ & $5.9(1 \cdot 3)$ & $5 \cdot 3(0.6)$ \\
\hline
\end{tabular}

Conversion: SI to traditional units-Glucose: $1 \mathrm{mmol} / 1 \approx 18 \mathrm{mg} / 100 \mathrm{ml}$. the second period they were allowed to accompany their mothers to the postnatal ward unless there were specific contraindications. Early feeding was standard practice throughout. Each infant's plasma glucose concentration was estimated on two occasions during the first six hours and every six hours for the subsequent 36 hours.

\section{Results}

There were no significant differences in age, parity, smoking habits, and social class distribution between mothers admitted in 1973-8 and those admitted in 1979-82. Mean maternal plasma glucose concentrations in each trimester indicated equally good diabetic control in both periods (table I). Seventeen of the 35 mothers in the first period and six of the $\mathbf{4 5}$ in the second were admitted, for an average of seven days, for stabilisation before 30 weeks' gestation. The average gestation at final admission to hospital, however, increased from 30 to 37 weeks, and the mean gestational age at delivery increased from 37.4 to 39.4 weeks.

The change in policy reduced the need for amniocentesis to assess fetal pulmonary maturity. In the first period studied 35 amniocenteses were performed in 26 patients. They were unsuccessful in two women, and seven women required two or more tests. In the second period four patients each had one amniocentesis.

Table II summarises the modes of delivery in the two periods. In the second period, in accordance with the change in policy, a larger proportion of patients went into spontaneous labour. Of these

TABLE III-Fetal outcome in the two periods

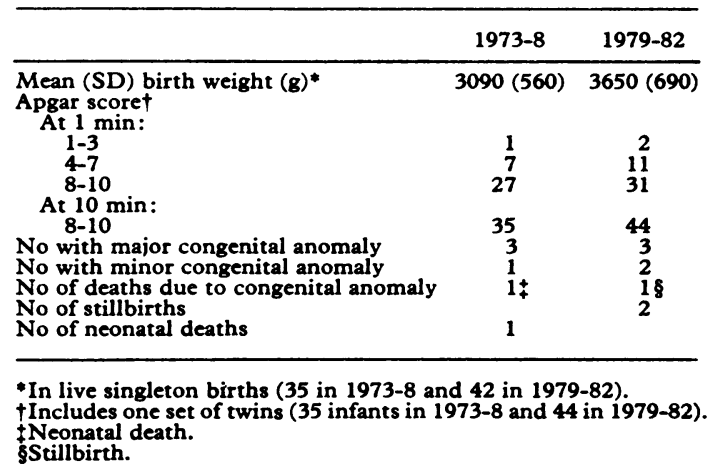

patients, $17(59 \%)$ delivered vaginally and 12 required emergency caesarean section (seven because of fetal distress, three because of disproportion, and two because the onset of labour had pre-empted elective sections). Also in accordance with the prevailing policy, elective induction of labour predominated from 1973 to 1978. Of 18 patients in whom labour was induced, $10(56 \%)$ delivered vaginally and eight $(44 \%)$ required caesarean section (four for fetal distress and four for failed induction. Of those patients at term in whom vaginal delivery was achieved, more were delivered by forceps in $1973-8(13 / 15 ; 87 \%)$ than in $1979-82(12 / 22 ; 55 \%)$.

Tables III and IV show fetal outcome. The mean birth weight increased from $3090 \mathrm{~g}$ to $3650 \mathrm{~g}$ after the change in policy. The pattern of Apgar scores and the incidence of hypoglycaemia were

TABLE II-Timing and mode of delivery in diabetic mothers before and after change in obstetric management

\begin{tabular}{|c|c|c|c|c|c|c|c|c|}
\hline & \multicolumn{4}{|c|}{$1973-8(n=35)$} & \multicolumn{4}{|c|}{$1979-82(n=45)$} \\
\hline & $\begin{array}{c}\text { No (\%) } \\
\text { deliveries }\end{array}$ & $\begin{array}{c}\text { Spontaneous } \\
\text { vaginal } \\
\text { delivery }\end{array}$ & $\begin{array}{l}\text { Forceps } \\
\text { delivery }\end{array}$ & $\begin{array}{l}\text { Emergency } \\
\text { caesarean section } \\
\text { in labour }\end{array}$ & $\begin{array}{c}\text { No (\%) } \\
\text { deliveries }\end{array}$ & $\begin{array}{c}\text { Spontaneous } \\
\text { vaginal } \\
\text { delivery }\end{array}$ & $\begin{array}{l}\text { Forceps } \\
\text { delivery }\end{array}$ & $\begin{array}{c}\text { Emergency } \\
\text { caesarean section } \\
\text { in labour }\end{array}$ \\
\hline \multirow{2}{*}{$\begin{array}{l}\text { Spontaneous term labour } \\
\text { Spontaneous preterm labour ( }<37 \text { weeks) } \\
\text { Elective induction of labour } \\
\text { Elective caesarean section } \\
\text { Emergency caesarean section in pregnancy }\end{array}$} & $5(14)$ & 1 & 4 & & \multirow{2}{*}{$\begin{array}{l}29(64) \\
2(4 \cdot 5) \\
3(7) \\
9(20) \\
2(4 \cdot 5)\end{array}$} & \multirow[t]{2}{*}{10} & \multirow{2}{*}{$\begin{array}{l}7 \\
2+ \\
3\end{array}$} & \multirow[t]{2}{*}{$12 *$} \\
\hline & $\begin{array}{c}18(51) \\
9(26) \\
3(9)\end{array}$ & 1 & 9 & 8 & & & & \\
\hline Total & 35 & 2 & 13 & 8 & 45 & 10 & 12 & 12 \\
\hline
\end{tabular}

Includes two patients in whom onset of labour pre-empted elective surgery.

Includes two patients in whom onset of labour pre-empte
+Includes one baby with a neural tube defect who died. 
similar in the two periods. A significantly greater proportion of infants in the first period were tube fed or required intravenous fluids $(p<0.001)$. The incidence of congenital abnormalities in the two groups was similar. In the first period there was one neonatal death due to pulmonary atresia. In the second period there were two stillbirths, one due to a neural tube defect, the other occurring unexpectedly at 39 weeks. This second stillbirth was in a 27 year old primigravida who had developed insulin dependent diabetes at 15 years of age. (White's class $C$.) At her first antenatal visit a goitre was noted and she was found to be hypothyroid. She was treated with borderline prematurity, ${ }^{3}$ reducing the need for admission to the special care baby unit and the resultant problems of separation. ${ }^{14}$

Although measurement of amniotic fluid surfactant has helped in timing delivery in diabetic women, ${ }^{15}$ the respiratory distress syndrome may still develop in 3\% of infants when the ratio of lecithin to sphingomyelin is above two. ${ }^{16}$ Delivery at term avoids this problem.

In conclusion, conservative management of pregnancy in diabetic women has several advantages. Perinatal mortality is

TABLE IV-Number $(\%)$ of term and preterm infants with neonatal complications in the two periods

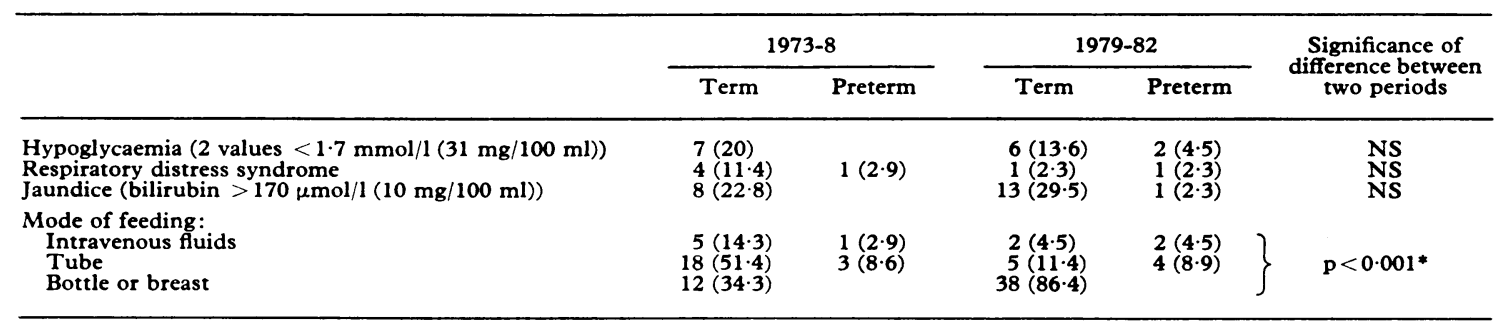

${ }^{*} x^{2}=23 \cdot 0$

thyroxine $0 \cdot 1 \mathrm{mg}$ daily. She was admitted for stabilisation for one week at 31 weeks and again at 37 weeks because of unsatisfactory diabetic control and polyhydramnios. The fetus died unexpectedly at 39 weeks while she was still in hospital. The cardiotocograph within the 12 hours preceding intrauterine death had been completely normal. Postmortem examination showed a fully mature, well nourished male fetus of $3460 \mathrm{~g}$. The only abnormality was a single umbilical artery. The woman subsequently completed a successful pregnancy, which was not included in this series.

\section{Discussion}

Effective management of pregnancy in diabetic mothers has been aided by self monitoring of blood glucose concentrations at home. On occasions this technique may be liable to error, and we therefore supervised its use with weekly checks of capillary blood concentrations. This resulted in satisfactory plasma glucose concentrations, and consequently the need for admission to hospital for diabetic control was reduced. These findings confirm the experience of others. ${ }^{56}$

Increasing confidence in the value of fetal movement charts, ? antenatal cardiotocography, ${ }^{8}$ and real time ultrasound scanning reduced the need to admit diabetic mothers to hospital for fetal assessment. It seems justifiable to allow those mothers in whom these tests yield satisfactory results to go to term.

Our changed policy had several effects on obstetric management. The need for amniocentesis to assess fetal pulmonary maturity was considerably reduced. This is an advantage because the procedure carries a risk in late pregnancy ${ }^{9}$ and bloody taps and failed amniocenteses are still problems despite improvements in ultrasonic techniques. ${ }^{10} 11$

There was an almost threefold increase in the proportion of mothers starting labour spontaneously and delivering vaginally after the new policy was introduced. Although the babies in the second period of study were $500 \mathrm{~g}$ heavier than those in the first, there was no increase in the proportion requiring delivery by forceps. Shoulder dystocia did not occur during either period, which may reflect our ready recourse to caesarean section if there was poor progress in the first stage of labour. Others have reported similar trends. ${ }^{12}$

There was one stillbirth at 39 weeks in the second period of study. The mother's hypothyroidism may have been a contributory factor, as a study of pregnant women with hypothyroidism showed a twofold increase in stillbirths compared with controls. ${ }^{13}$

Late delivery avoids the complications associated with not appreciably increased, and morbidity is reduced owing to the greater maturity of the babies. The mothers much prefer this form of management, which has obvious social and domestic advantages, especially for those who already have young children. Finally, there are financial savings in avoiding antenatal admission to hospital for periods of up to 10 weeks.

\section{References}

${ }^{1}$ Persson B, Gentz J. Metabolic observations during neonatal life. In: Camerini-Davalos $\mathrm{R}$, Cole $\mathrm{H}$, eds. Early diabetes in early life. New York: Academic Press, 1975:547-55.

${ }_{2}$ Merkatz IR, Fanaroff AA. Antenatal and intrapartum care of the high risk neonate. In: Klaus $\mathrm{MH}$, Fanaroff AA, eds. Care of the high risk neonate. Philadelphia: W B Saunders, 1979:1-22.

3 Usher R. The special problems of the premature infant. In: Avery GB, ed. Neonatology. Philadelphia: J B Lippincott, $1981: 230-61$.

4 Gamsu HR. Neonatal morbidity in infants of diabetic mothers. $\mathcal{F} R$ Soc Med 1978;71:211-22.

5 Peacock I, Hunter JC, Walford S, et al. Self monitoring of blood glucose in diabetic pregnancy. $\mathrm{Br}$ Med 7 1979;ii:1333-6.

${ }^{6}$ Stubbs SM, Brudenell JM, Pyke DA, Watkins PJ. Management of the pregnant diabetic: home or hospital, with or without glucose meters. Lancet $1980 ; \mathrm{i}: 1122-4$

${ }^{7}$ Pearson JF, Weaver JB. Fetal activity and fetal wellbeing: an evaluation. Br Med f 1976; i:1305-7.

${ }^{8}$ Pearson JF, Weaver JB. A six-point scoring system for antenatal cardiotocographs. Br $\mathcal{F}$ Obstet Gynaecol 1978;85:321-7.

${ }^{9}$ Rome RM, Glover JI, Simmons SC. The benefits and risk of amniocentesis for the assessment of fetal lung maturity. Br $\mathcal{F}$ Obstet Gynaecol $1975 ; 82: 662-8$

${ }^{10}$ Platt LD, Manning FA, Lemay M. Real time B-scan-directed amniocentesis. Am 7 Obstet Gynecol 1978;130:700-3.

11 Manning FA, Morrison I, Lange IR, Hurman CR. Antepartum evaluation of fetal health. In: Chiswick ML, ed. Recent advances in perinatal medicine. Edinburgh: Churchill Livingstone, 1983:41-56.

12 Drury MI, Stronge JM. Diabetes mellitus and pregnancy. In: Bonnar J ed. Recent advances in obstetrics and gynaecology. Edinburgh: Churchill Livingstone, 1982:95-111.

${ }^{13}$ Innerfield F, Hollander CS. Thyroidal complications of pregnancy. Med Clin North Am 1977;61:67-87.

14 Richards MPM. Possible effects of early separation on later development of children. In: Brimblecombe FSW, Richards MPM, Roberton MRC, eds. Separation and special care baby units. London: Spastics International Medical Publications, Heinemann, 1978:12-32.

${ }^{15}$ Agrombuoi J, Mann LI, Weiss RR, Tejani NA, Paydar M. Modern management of the diabetic pregnancy. Am $\mathcal{f}$ Obstet Gynecol 1977; 49:137-43.

${ }^{16}$ Gabbe SG, Lowensohn RI, Westman JW, Freeman RK, Goebelsmann W. Lecithin/sphingomyelin ratio in pregnancy complicated by diabetes. Am F Obstet Gynecol 1975;128:757-70. 